\title{
Investigating the early-age diffusion of chloride ions in hardening slag-blended mortars on the light of their hydration progress
}

\author{
Amor Ben Fraj ${ }^{\mathrm{a}, *}$, Stéphanie Bonnet ${ }^{\mathrm{b}}$, Nordine Leklou ${ }^{\mathrm{b}}$, Abdelhafid Khelidj ${ }^{\mathrm{b}}$ \\ ${ }^{a}$ Cerema, Project-team DIMA, 120 rue de Paris, BP 216 Sourdun, 77487 Provins Cedex, France \\ ${ }^{\mathrm{b}}$ UBL, Université de Nantes, GeM, CNRS UMR 6183, 58 rue Michel Ange (BP 420), 44606 Saint Nazaire Cedex, France
}

\begin{abstract}
The present work seeks to investigate the ingress of chlorides during the hardening of slag-blended mortars that may have been exposed to chlorides since an early age. In order to correlate chloride ingress with the microstructure development, both the hydration reaction and chemical shrinkage of the investigated mixtures are monitored, and their microstructure is characterized through SEM observations. Results indicate a slow hydration reaction in the presence of slag, which decelerates the formation of hydrates and the filling of capillary pores. Despite the decrease in chemical shrinkage, chloride ingress still increases, thus amplifying the risk of corrosion in slag-blended matrices. The hydrates gradually develop within the hardening microstructure and obstruct the chloride diffusion paths, resulting in a lower chloride diffusion coefficient. The apparent chloride-diffusion coefficient measured after 28 days of exposure is $12 \times 10^{-12} \mathrm{~m}^{2} / \mathrm{s}, 14.2 \times 10^{-12} \mathrm{~m}^{2} / \mathrm{s}$ and $14 \times 10^{-12} \mathrm{~m}^{2} / \mathrm{s}$ for hardening mortars, with respectively $0 \%, 30 \%$ and $60 \%$ of slag. These coefficients are respectively 2 times, 2.8 times and 4.7 times higher than those of hardened mortars.
\end{abstract}

\section{Introduction}

As regards structures built in a marine environment, concrete may rapidly come into contact with seawater (i.e. through repair materials, leaks in the formwork or its early removal). At an early age, the hydrating cementitious matrix shows relatively high porosity, which then gradually decreases as hydrates develop within the hardening microstructure [1]. This high initial porosity amplifies the risk of the chloride contamination of concrete, especially in the case of early formwork removal. In addition, during the first few days after their fabrication, cement-based materials undergo major volume changes, even in the absence of external loading. Under certain structural conditions, these deformations are severe enough to cause premature (micro)cracking of the concrete. This microcracking can subsequently increase porous net-

\footnotetext{
* Corresponding author.
}

work connectivity, therefore accelerating the ionic diffusion phenomena in the material.

The combination of early formwork removal and restrained early-age deformations constitutes favorable conditions for chloride penetration into the hardening concrete microstructure [2$4]$. The corrosion of rebar and degradation of the cementitious matrix could arise and compromise the long-term performance of the concrete structure. This phenomenon depends heavily on the concrete composition and curing conditions; the type of binder is also a key parameter [5-12]. Recent advances and the emergence of environmental considerations behind sustainable development have highlighted the large amount of $\mathrm{CO}_{2}$ emissions generated by the production of Portland cement. In this context, promoting alternative binders, in which clinker is replaced by mineral admixtures, offers a promising solution [13-16]. Such binders are considered as byproducts (blast furnace slag (BFS), fly ash (FA), silica fume (SF), pozzolan) and contribute to improving the long-term performance of concrete, in both mechanical and durability terms (i.e. against 
chloride attack) $[15,16]$. Blast furnace slag is extensively used in marine environments. Due to their fineness, BFS particles further refine the porous network, increase its tortuosity [1] and enhance the concrete with higher compressive strength and resistance to aggressive agents [6,17-20]. Nevertheless, their incorporation, notably in high volumes, greatly decreases the early-age performance of concrete. By virtue of their slow reaction, BFS particles decelerate the hydration reaction in a blended matrix and delay its rise in compressive strength [21-23]; moreover, the chemical shrinkage is decreased [24]. In the presence of this mineral admixture, the binder exhibits high porosity at an early age, which in turn raises the risk of aggressive agent ingress, as reported in [4].

Although many studies have focused on the early-age properties of BFS-blended materials, since these properties govern longterm durability, unfortunately an insufficient amount of data is available regarding the behavior of these materials when placed in contact with an aggressive environment at an early age. Over the upcoming years, this topic should receive greater attention. The stock of civil engineering structures is aging and, coupled with economic constraints, we will be relying more extensively on repairs in order to avoid having to dismantle these structures. This phenomenon also applies to strategic facilities, whose closure (due to rehabilitation works) could imperil economic activity. The materials used in such operations are typically quickly exposed to aggressive agents in the surrounding environment. Given this context, the proposed research focuses on chloride diffusion in hardening slag-blended cementitious matrices exposed to a saline solution as of their very early age $(24 \mathrm{~h})$. These blended matrices could be used as structural or repair materials for structures in a marine environment. Four mortars with different slag and sand contents are investigated herein. The novelty of this research work is to correlate the derived chloride profiles with the hydration progress of the mortars, their microstructure evolution and chemical shrinkage (Fig. 1). A comparison with hardened samples is carried out in order to quantify the effect of hydration progress on the apparent chloride diffusion coefficient.

\section{Experimental program}

\subsection{Materials}

The four mortars are prepared with calcareous sand $(0 / 4 \mathrm{~mm})$, at a water absorption of $0.9 \%$. All mixes are made with the same Portland cement (CEM I $52.5 \mathrm{~N}$ PM ES) from the Le Havre plant (France), with a specific area of $3820 \mathrm{~cm}^{2}$ / $\mathrm{g}$ and a bulk density of $3180 \mathrm{~kg} / \mathrm{m}^{3}$. The first mortar contains only Portland cement, while the others contain Portland cement and BFS at different percentages. The blast furnace slag is from Moerdijk (the Netherlands); its specific surface area and bulk density are $4620 \mathrm{~cm}^{2} / \mathrm{g}$ and $2890 \mathrm{~kg} / \mathrm{m}^{3}$, respectively. Table 1 lists the cement and slag chemical compositions and the mass fractions of the primary cement phases.

\subsection{Mixtures}

To highlight the effect of slag on both microstructure and chloride diffusion at an early age, the granular inclusion concentration is held constant (Sand/Binder $=1$ ) and two BFS contents are tested: the first one (30\%) corresponds to the maximum rate authorized by European Standard EN 206 [25], and the second is twice the first (60\%) for the purpose of demonstrating the effect of high BFS content on the earlyage properties of slag-blended mortars. Two granular inclusion contents are then compared (Sand/Binder $=1$ and Sand/Binder $=2$ ) for the mixture with $30 \%$ slag.

The mortars are prepared by mixing the solid components with water in a 5-L mixer, according to the procedures and mixing times detailed in Fig. 2 . The various mixtures investigated are summarized in Table 2; they are denoted CiBFSjSk, where $i, j$ and $k$ are the mass percentage of cement in binder, mass percentage of BFS in binder and the sand-to-binder ratio, respectively.

\subsection{Testing methods}

After demolding, all specimens are water-stored before testing. During this research, all the experimental tests are conducted at room temperature, i.e. between $19^{\circ}$ and $21^{\circ} \mathrm{C}$. The various tests and their corresponding curing ages are

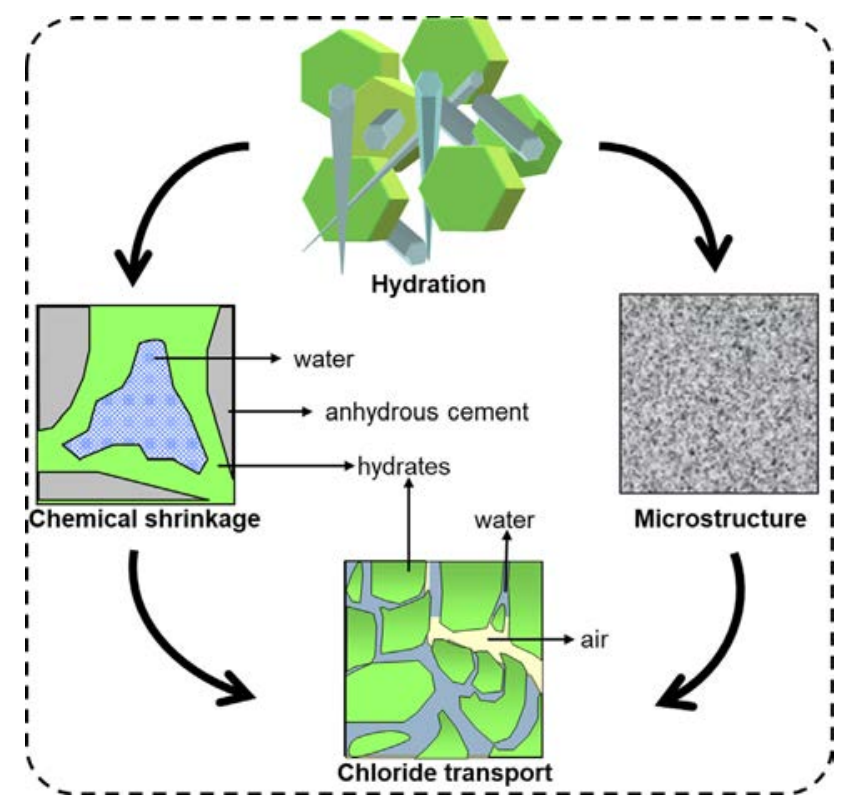

Fig. 1. Chloride transport vs hydration progress.

Table 1

Chemical composition of cement and slag.

\begin{tabular}{lll}
\hline \multirow{2}{*}{ Compounds } & \% (by weight) & \\
\cline { 2 - 3 } & Cement & Slag \\
\hline $\mathrm{CaO}$ & 64.95 & 41.03 \\
$\mathrm{SiO}_{2}$ & 21.25 & 34.49 \\
$\mathrm{Al}_{2} \mathrm{O}_{3}$ & 3.47 & 13.19 \\
$\mathrm{Fe}_{2} \mathrm{O}_{3}$ & 4.23 & 0.40 \\
$\mathrm{MgO}$ & 0.96 & 8.21 \\
$\mathrm{~K}_{2} \mathrm{O}$ & 0.28 & 0.54 \\
$\mathrm{Na}_{2} \mathrm{O}$ & 0.10 & 0.43 \\
$\mathrm{SO}_{3}$ & 2.63 & 0.10 \\
$\mathrm{Bogue}$ 's composition (mass percentage) & \\
$\mathrm{C}_{3} \mathrm{~S}$ & 67.5 & - \\
$\mathrm{C}_{2} \mathrm{~S}$ & 10.7 & - \\
$\mathrm{C}_{3} \mathrm{~A}$ & 2.64 & - \\
$\mathrm{C}_{4} \mathrm{AF}$ & 12.8 & - \\
$\mathrm{Gypsum}$ & 3.30 & - \\
\hline & &
\end{tabular}

listed in Table 3. For chloride diffusion, all hardening specimens are cured for one day (in a mold), then demolded (after $24 \mathrm{~h}$ ) and directly chloride-exposed for 1 7, 14 and 28 days. Hardened mortars are water-cured for up to 28 days and then exposed to chlorides for another 28 days.

\subsubsection{Heat of hydration}

The heat flow resulting from mortar hydration reactions is measured using a TAM Air isothermal microcalorimeter. For each specimen examined, two 5 to $6 \mathrm{~g}$ specimens are extracted at the end of mixing, accurately weighed (to within $0.01 \mathrm{~g}$ ) and placed into small flasks. These flasks are then sealed and inserted into the apparatus. Each test is performed during the first 7 days of hydration. The first data point is acquired approx. ten minutes after the end of mixing. It is assumed that over this time, the non-recorded heat of hydration remains low compared to the total heat release.

Eq. (1) is used to calculate the degree of hydration:

$\alpha=\frac{Q(t)}{Q_{\infty}(\text { Binder })}$

where $Q(t)$ is the heat of reaction (J/g of binder) versus time $t(\mathrm{~s})$, and $Q_{\infty}$ (Binder) the total heat of reaction as tends to $\infty$.

Calculating the degree of hydration requires knowing $Q_{\infty}$ (Binder). In this study, $Q_{\infty}$ (Binder) is calculated from the composition of the binder (\% of cement and slag):

$Q_{\infty}($ Binder $)=f_{\text {Cement }} \cdot Q_{\infty}($ Cement $)+f_{B F S} \cdot Q_{\infty}(B F S)$ 


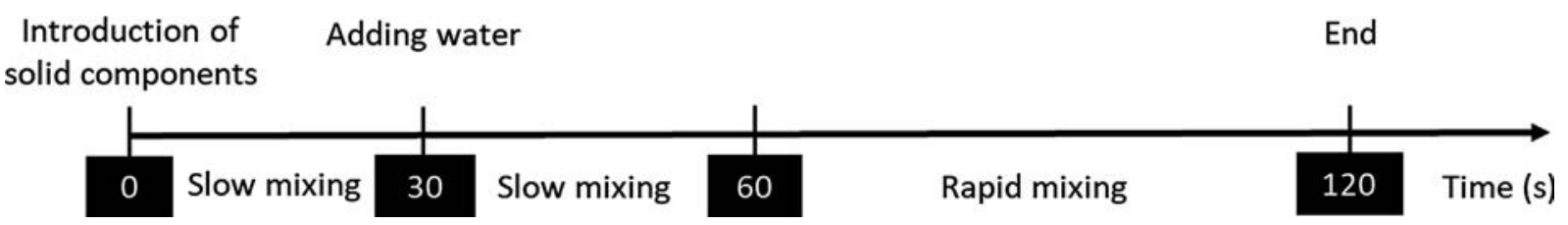

Fig. 2. Mixing procedure.

Table 2

Mix proportions.

\begin{tabular}{lllll}
\hline Constituents (g/g of binder) & Cement & Slag & Sand & Water \\
\hline C100BFS00S1 & 1 & - & 1 & 0.48 \\
C70BFS30S1 & 0.7 & 0.3 & 1 & 0.48 \\
C70BFS30S2 & 0.7 & 0.3 & 2 & 0.48 \\
C40BFS60S1 & 0.4 & 0.6 & 1 & 0.48 \\
\hline
\end{tabular}

Table 3

Experimental program.

\begin{tabular}{|c|c|c|c|c|}
\hline \multirow[t]{2}{*}{ Tests } & \multicolumn{4}{|c|}{ Age of curing/ exposure time ${ }^{*}$ (days) } \\
\hline & 1 & 7 & 14 & 28 \\
\hline Isothermal micro-calorimetry & $\leftarrow$ & . & & \\
\hline Thermogravimetric Analysis & + & + & + & + \\
\hline Chemical shrinkage & $\leftarrow$ & & & \\
\hline SEM observations & + & & + & + \\
\hline Compressive strength & + & + & + & + \\
\hline Chloride diffusion $^{*}$ & + & + & + & + \\
\hline
\end{tabular}

where $f_{\text {Cement }}$ and $f_{B F S}$ are the mass fractions of cement and slag, respectively. $Q_{\infty}$ (Cement) and $Q_{\infty}$ (BFS) are the heat of reactions $(\mathrm{J} / \mathrm{g}$ ) of cement and slag, respectively. For simplification, it is assumed that the total heat of reaction for the binder is the sum of its components' heats and no interaction is considered.

The heat of reaction of cement can be calculated from its main components and their mass fractions [26]. For slag, the data on heat of reaction remain scarce and depend on the material composition. The values used were proposed by Kishi and Maekawa [27], who suggested a heat of reaction at $\infty$ equal to $461 \mathrm{~J} / \mathrm{g}$. Consequently, we have obtained a heat of reaction at $\infty$ of $487 \mathrm{~J} / \mathrm{g}$ when cement is the only binder component. For partial substitution rates of $30 \%$ and $60 \%$ of cement by slag, the heat of reaction of binder at $\infty$ amounts to $479 \mathrm{~J} / \mathrm{g}$ and $471 \mathrm{~J} / \mathrm{g}$, respectively.

\subsubsection{Thermo-gravimetric analysis (TGA)}

TGA is used to assess the evolution of the non-evaporable water in the tested materials. These tests are conducted on $250-300 \mathrm{mg}$ samples subjected to a temperature of up to $1050^{\circ} \mathrm{C}$. All samples are stored in water and after $1,7,14$ and 28 days of hydration, a portion of the sample is crushed, ethanol-immersed (to stop the hydration) and oven-dried. The sample is then powdered and sieved using a $315-\mu \mathrm{m}$ sieve before proceeding with a TGA.

\subsubsection{Microstructural observations}

To simulate the actual microstructural evolution of cementitious materials in their respective environments, the samples are water-cured and their microstructure investigated after 1, 14 and 28 days of curing. An environmental electron microscope is used to avoid drying the samples, which could modify their microstructure. The same sample is characterized for all curing periods.

Two levels of magnification were used: $\times 90$ and $\times 10000$. The former allows observing the level of macrocracking induced by hydration reactions and then shrinkage, while the latter pertains to the anhydrous and hydrates formed, particularly Portlandite and calcite, depending on mix composition.

\subsubsection{Chemical shrinkage}

In this study, chemical shrinkage measurements are carried out using a gravimetric method [28]. From the end of mixing, a $\approx 10$-g cementitious paste sample is introduced into a plastic flask. Then, accompanied by manual vibration, the entrapped air bubbles are flushed out. The remaining empty flask volume is filled with distilled and deaerated water in making sure not to disturb the sample. The flask is then closed and a small orifice in the flask cap allows for a continuous water supply. The flask is hung on a scale (accurate to within $0.001 \mathrm{~g}$ ) by a nylon thread and immersed in distilled water. Next, the experimental device is placed in a room maintained at $20^{\circ} \pm 2^{\circ} \mathrm{C}$. The weighting starts 15 min after mixing and lasts $168 \mathrm{~h}$ (i.e. 7 days).

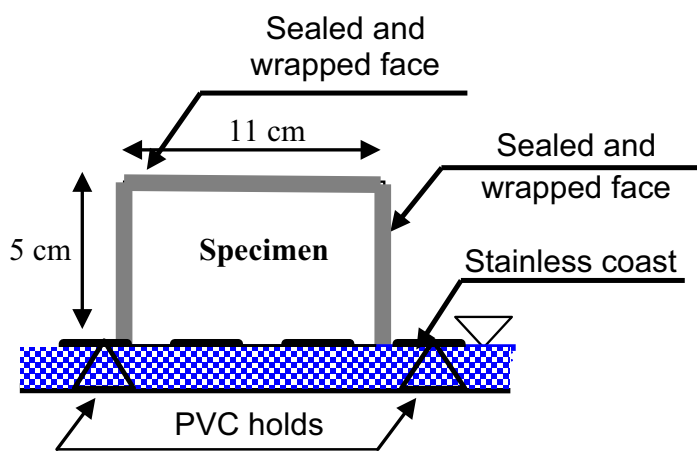

Fig. 3. Samples in contact with chloride solution.

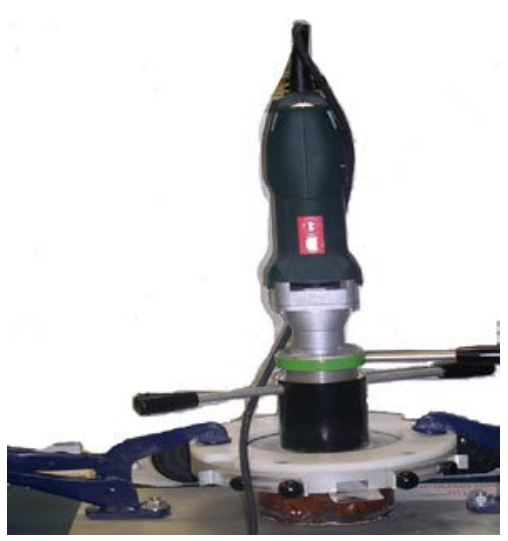

Fig. 4. Grinding instrument.

\subsubsection{Mechanical properties}

The compressive strength is measured on $4 \times 4 \times 16 \mathrm{~cm}^{3}$ samples at $1,7,14$ and 28 days, in accordance with EN 196-1 [29]. Samples are cast, unmolded after 1 day and stored in water until testing.

\subsubsection{Chloride diffusion}

After demolding, the samples with $5 \mathrm{~cm}$ of height and $11 \mathrm{~cm}$ of diameter are placed in a basic solution ( $1 \mathrm{~g} / \mathrm{l}$ of $\mathrm{NaOH}+4.65 \mathrm{~g} / \mathrm{l}$ of $\mathrm{KOH}$ ) containing $30 \mathrm{~g} / \mathrm{l} \mathrm{of} \mathrm{NaCl}$, up to $0.2 \mathrm{~cm}$ (Fig. 3). The size $5 \mathrm{~cm}$ was chosen as it is corresponding to concrete cover depth for marine reinforced structures. The samples were sealed and wrapped except on the surface, which is in contact with chloride solution to get a one-dimensional transport and to be in accordance with the cover concrete conditions.

After exposure ( $1,7,14$ and 28 days), the cores are removed from the immersion tank to be ground in several steps of $3 \mathrm{~mm}$ each, perpendicular to the top faces of the cylinders, using the grinding instrument (Fig. 4) recommended by Vennesland et al. [30]. Lastly, the powder is collected and stored in sealed plastic bags. The procedure recommended by RILEM Technical Committee 178-TMC [31] is followed in order to obtain the total chloride profiles; approximately $5 \mathrm{~g}$ of concrete powder is extracted from each layer and placed in a beaker with $\mathrm{HNO}_{3}$ and deionized water. The mixture is stirred and heated to $80^{\circ} \mathrm{C}$ for $30 \mathrm{~min}$. The solution is then filtered and the chloride concentration determined by means of potentiometric titration using an automatic titrator with $0.05 \mathrm{M}$ silver nitrate $\left(\mathrm{AgNO}_{3}\right)$. Based on a recent study by Bonnet et al. [32], the standard deviation for total chloride content equals approximately $6 \%$ (calculated from 42 measurements). 


\section{Results}

\subsection{Microstructural development}

\subsubsection{Hydration reaction}

The hydration reaction results presented in this paper are the average curves obtained on two specimens for each cementitious mixture analyzed.

Fig. 5 displays the evolution in both the heat flow of hydration and heat of reaction monitored by isothermal microcalorimetry. As shown, the replacement of cement by BFS causes a reduction in the magnitude of the peak heat flow. This phenomenon is directly correlated with the dilution effect of slag plus the fact that both hydraulic and pozzolanic reactions release less heat than Portland cement hydration $[21,33,34]$. The second peak, observed by other authors [23], characterizes the contribution of slag to the hydration reaction; this contribution is not readily apparent given that the studied materials are mortars and the binder volume is small. The curves plotted however reveal that the peak heat flow becomes flatter as slag content rises $[23,35]$. Table 4 indicates both the measured and normalized characteristic values of the isothermal microcalorimetry curves; the substitution of cement by $30 \%$ and $60 \%$ slag results in a decrease of $18 \%$ and $51 \%$ of the primary peak heat flow, respectively. The results obtained follow the same trend as that of Mounanga et al. [21] and Ballim et al. [35].

As regards heat release, incorporating BFS decreases the measured heat at 24 h by $13 \%$ and $45 \%$, for $30 \%$ and $60 \%$ cement substitution rates respectively. These results lie close to those obtained by Mounanga et al. [21], Wang et al. [36] and Merzouki et al. [24].

Since the degree of reaction is proportional to heat release, at $24 \mathrm{~h}$ a $13 \%$ and $43 \%$ decrease in the degree of reaction has been shown (Fig. 6) when cement is substituted by BFS at rates of $30 \%$ and $60 \%$, respectively. From one day and up to 7 days, BFS is reacting slowly. Nevertheless, the difference in hydration progress and its delay is notable between 1 and 7 days for slag blended matrices in comparison with reference one. Indeed, from 1 to 7 days, the degree of hydration of C100BFS00S1 doubled, while that of C40BFS60S1 tripled.

The results obtained are in agreement with those of the TGA tests (Fig. 7), thus indicating an increase in the bound water over time for all tested mixtures and a decrease with respect to BFS content. The amount of bound water is an index of hydration progress and strength development (see Section 3.1.3. on compressive strength). A low bound water content in BFS-blended mixtures can therefore be explained by the latent effect of BFS particles on the hydration reaction. This same trend was found by Bouasker [37].

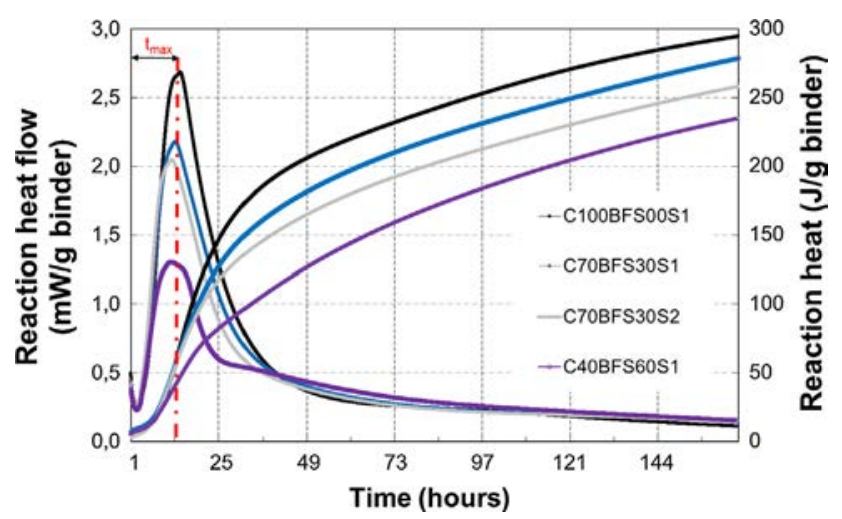

Fig. 5. Reaction heat and reaction heat flow versus time for OPC and slag-blended mortars.
As regards the concentration of granular inclusions, hydration reaction results display a slight acceleration as the sand content increases (C70BFS30S2). Two reasons can explain this behavior: i) the "site effect" promoted by the presence of fine particles in sand $(<100 \mu \mathrm{m})$, acting as additional nucleation sites for hydrates [38]; and ii) the "dispersion effect" as sand particles destroy the cement blocks, inducing a better dispersion of cement grains, which in turn results in rapid hydration [38].

\subsubsection{SEM observations}

To determine the influence of BFS on the microstructure, cement pastes with a water-to-cement ratio of 0.48 were manufactured and characterized at different curing times (1, 14 and 28 days) using a Scanning Electron Microscope (SEM) so as to observe their morphology (Fig. 8). Regarding the microstructure, after 1 day of hydration, no significant difference is observed between the C100BFS00 and C40BFS60 (with 60\% slag) cement pastes. At 14 days of hydration, the cement paste microstructure when mixed with BFS is more compact than that without BFS, and many plate-shaped calcium hydroxide crystals are noticed throughout the sample, as opposed to the C100BFS00 cement paste sample. The C40BFS60 sample also contains a number of unhydrated slag particles lying in close contact with the surrounding cement paste [39]. At 28 days of hydration, the C40BFS60 microstructure becomes denser, and microcracking decreases as considerably more $\mathrm{C}-\mathrm{S}-\mathrm{H}$ gel fills the pores, forming an aggregated homogeneous gel; meanwhile, the $\mathrm{Ca}(\mathrm{OH})_{2}$ content decreases due to the pozzolanic effect. This finding indicates a higher degree of reaction on the slag particle surface $[40,41]$, as demonstrated by the hydration reaction results.

The SEM observations agree with the results of Whittaker et al. [42] and those of Ogirigbo and Black [43]. The formers showed that slags hydrate more slowly than Portland cement clinker and observed higher porosity at an early age than in the long term. The work explains that in the later ages, the inner product $\mathrm{C}-\mathrm{S}-\mathrm{H}$ is more abundant, surrounding the partially hydrated larger grains. The finer slag particles had fully reacted leaving only partially hydrated larger ones with characteristic hydration rims. With increasing hydration, the total pore area reduced.

\subsection{Chemical shrinkage}

Fig. 9 presents the evolution in chemical shrinkage for the various mixtures under investigation. Each curve depicts the average of measurements obtained on two specimens. This section will discuss the effects of BFS content and granular inclusion concentration on the chemical shrinkage of cement- and slag-blended mortars.

For the same $\mathrm{S} / \mathrm{C}$ ratio, mortars incorporating BFS feature less chemical shrinkage during the first few days. Subsequently as hydration progresses, the difference between the reference mortar and those with $30 \%$ and $60 \%$ BFS is reduced until completely disappearing at $192 \mathrm{~h}$. Up to $72 \mathrm{~h}$, the chemical shrinkage is indeed increasing, reaching $35 \mathrm{~mm}^{3} / \mathrm{g}$ of cement for C100BFS00S1. For C70BFS30S1 and C40BFS60S1, the chemical shrinkage of binder equals respectively $30 \mathrm{~mm}^{3} / \mathrm{g}$ and $25 \mathrm{~mm}^{3} / \mathrm{g}$. After $72 \mathrm{~h}$, the BFS reaction occurs and accelerates more sharply after 7 days, leading to additional shrinkage. As a result, the chemical shrinkage of C70BFS30S1 equals that of the reference mortar $\left(45 \mathrm{~mm}^{3} / \mathrm{g}\right.$ of cement) at $192 \mathrm{~h}$. Lura et al. [44] explained this effect by the finer pore distribution of slag-cement pastes, which increases the capillary depression, thus inducing more pronounced shrinkage. A second cause of the higher strain of the blended matrix would be the lower Young's modulus of a slag-cement mixture [45]: subjected to an identical internal capillary tension, this type of mixture will shrink more than a cement mixture. Merzouki et al. [24] observed 
Table 4

Hydration characteristics of characterized mortars.

\begin{tabular}{|c|c|c|c|c|c|c|}
\hline \multirow[t]{2}{*}{ Mortars } & \multicolumn{2}{|c|}{ Time of maximum heat flow $t_{\max }$} & \multicolumn{2}{|c|}{ Maximum intensity of heat flow $\mathrm{I}_{\max }$} & \multicolumn{2}{|c|}{ Degree of reaction at age $=24 \mathrm{~h}$} \\
\hline & $\begin{array}{l}\text { Measured } \\
\text { value } t_{\max }(\min )\end{array}$ & $\begin{array}{l}\text { Normalized } \\
\text { value } \frac{t_{\max }}{t_{\max }(R e f)}(-)\end{array}$ & $\begin{array}{l}\text { Measured value } \\
\mathrm{I}_{\max }(\mathrm{mW} / \mathrm{g} \text { of binder })\end{array}$ & $\begin{array}{l}\text { Normalized value } \\
\frac{I_{\max }}{I_{\max }(R e f)}(-)\end{array}$ & $\begin{array}{l}\text { Calculated value } \\
\alpha_{24 \mathrm{~h}}(\%)\end{array}$ & $\begin{array}{l}\text { Normalized value } \\
\frac{\alpha_{24 h}}{\alpha_{24 h}(\operatorname{Ref})}(-)\end{array}$ \\
\hline C100BFS00S1 (Ref) & 855 & 1.00 & 2.68 & 1.00 & 30 & 1.00 \\
\hline C70BFS30S1 & 771 & 0.90 & 2.18 & 0.81 & 26 & 0.87 \\
\hline C70BFS30S2 & 711 & 0.83 & 2.05 & 0.76 & 24 & 0.80 \\
\hline C40BFS60S1 & 699 & 0.82 & 1.3 & 0.49 & 17 & 0.57 \\
\hline
\end{tabular}

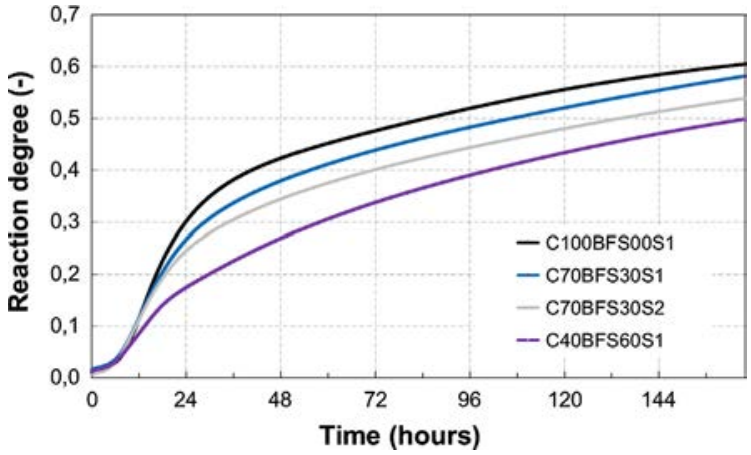

Fig. 6. Reaction degree versus time for OPC and slag-blended mortars.

this same trend for blended cement with $\mathrm{a} w / \mathrm{b}=0.32$ and different BFS contents.

In comparing the behavior of C70BFS30S1 with that of C70BFS30S2, we note a sharp increase in chemical shrinkage with the concentration of granular inclusions. Three effects give rise to this increase: site effect, dispersion effect, and tank effect. Both the site and dispersion effects promote the hydration of cement particles, inducing more extensive chemical shrinkage. The tank effect pertains to the aggregates used in their dry state; these aggregates absorb water during mixing and after setting, with the self-desiccation phenomenon inducing capillary forces that promote the transport of water from aggregates to partially saturated pores of the cement matrix [38,46,47], resulting in increased chemical shrinkage.

\subsection{Compressive strength}

Fig. 10 plots the compressive strength versus curing age for various sand and BFS contents. For each mixture, uncertainties are calculated using 95\% confidence intervals of all 6 tests. As expected, compressive strength at an early age decreases with BFS content. The compressive strength of C40BFS60S1 is especially low (6.8 MPa and $28.8 \mathrm{MPa}$ at 2 and 7 days, respectively). This result is in agreement with findings from both the hydration reaction and TGA analysis, i.e. featuring a low heat release and chemically-bound water, which denotes a slow hydration reaction and more limited compressive strength. Later on, the BFS reaction is promoted by the Portlandite produced from the cement reaction. The C-S-H formed thus fill the capillary pores and improve the compressive strength of the blended matrix [20]. Consequently, at 28 days, the compressive strength of C7OBFS30S1 resembles that of C100BFS00S1 (in considering the uncertainties).

As regards the effect of granular inclusions, C70BFS30S2 exhibits greater compressive strength than C70BFS30S1, at every age. This difference is more pronounced at 28 days: the compressive strengths of C70BFS30S2 and C70BFS30S1 are respectively $60 \mathrm{MPa}$ and $50 \mathrm{MPa}$. At an early age, the sand particles actually improve the hydration reaction of cement by virtue of their site and dispersion effects. At later ages, the sand particles act as a tank,

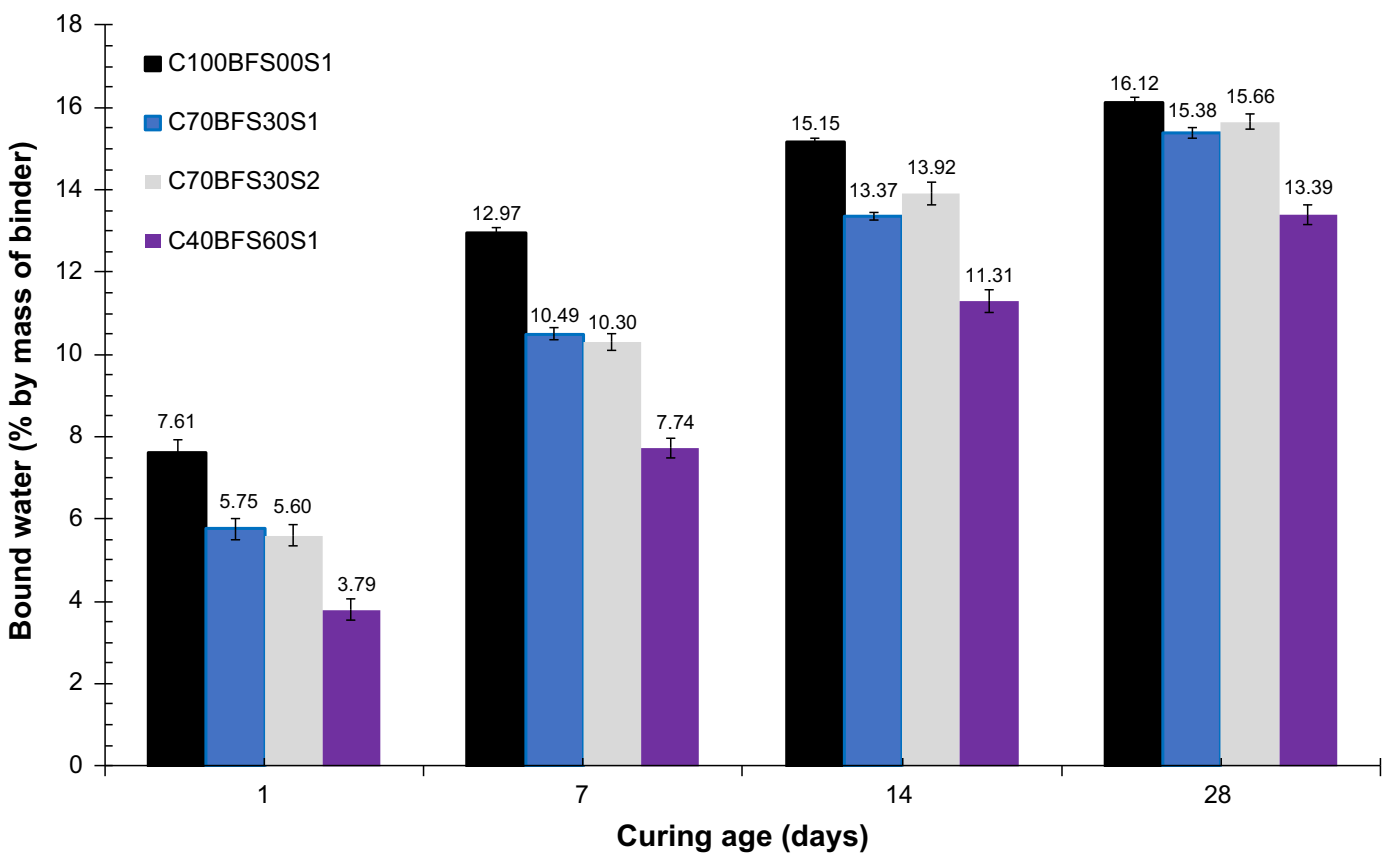

Fig. 7. Bound water of OPC and slag-blended mortars. 


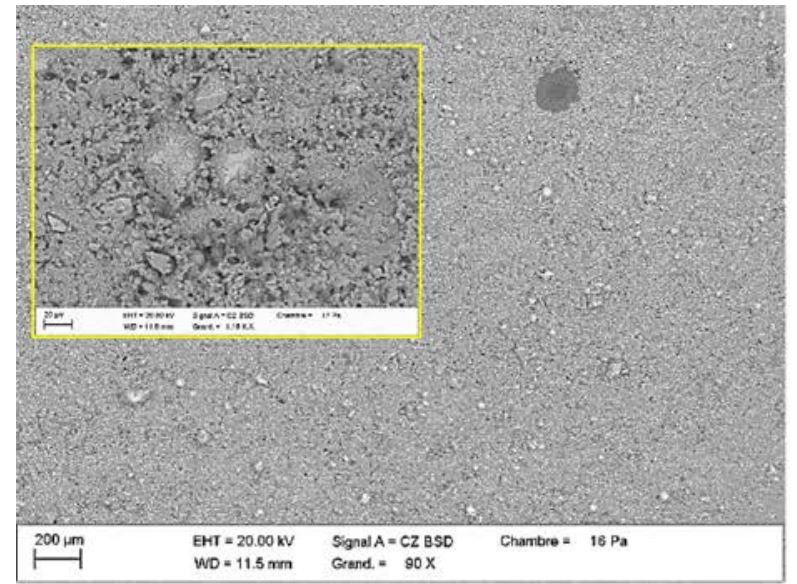

C100BFS00_1 day

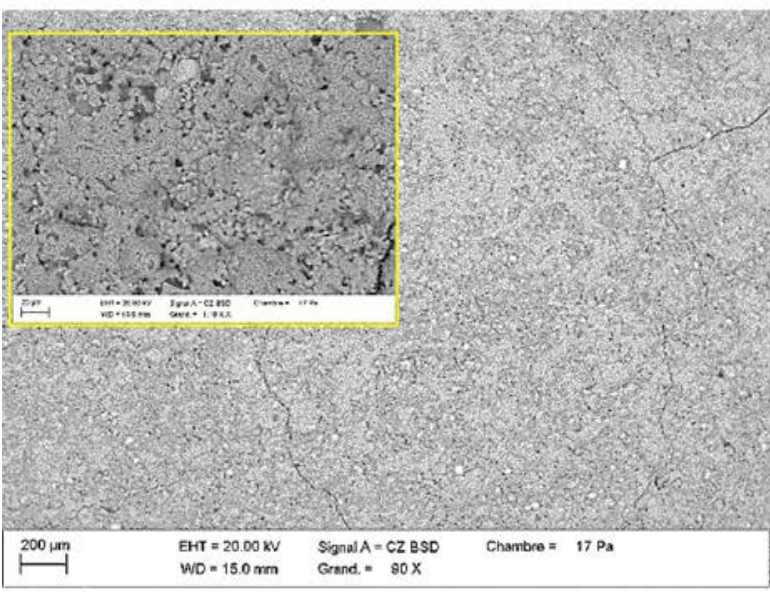

C100BFS00_14 days

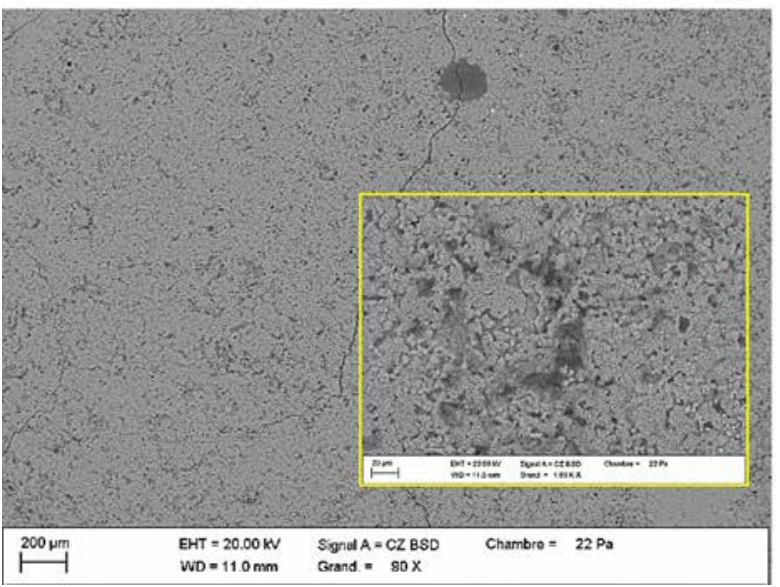

C100BFS00_28 days

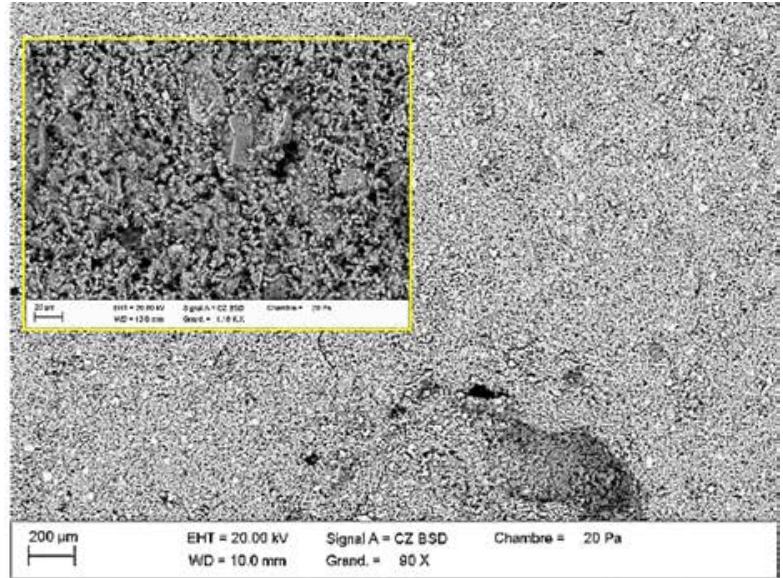

C40BFS60_1 day

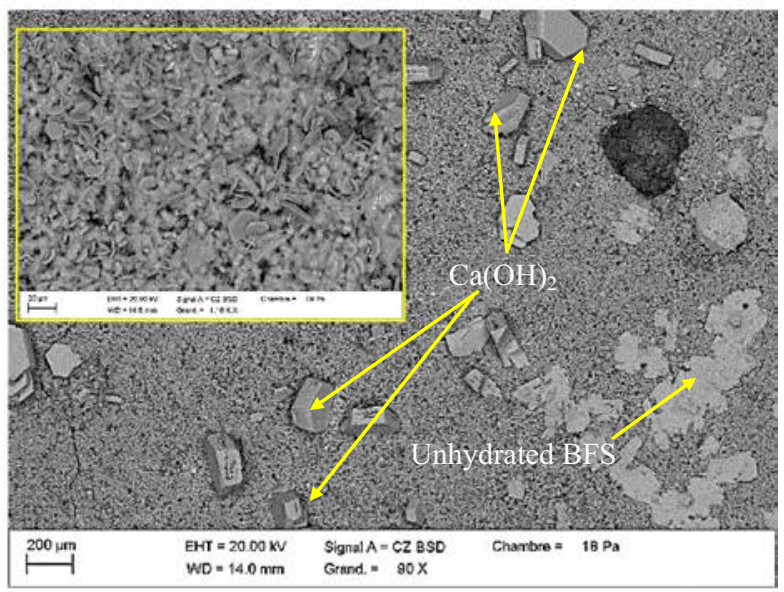

C40BFS60_14 days

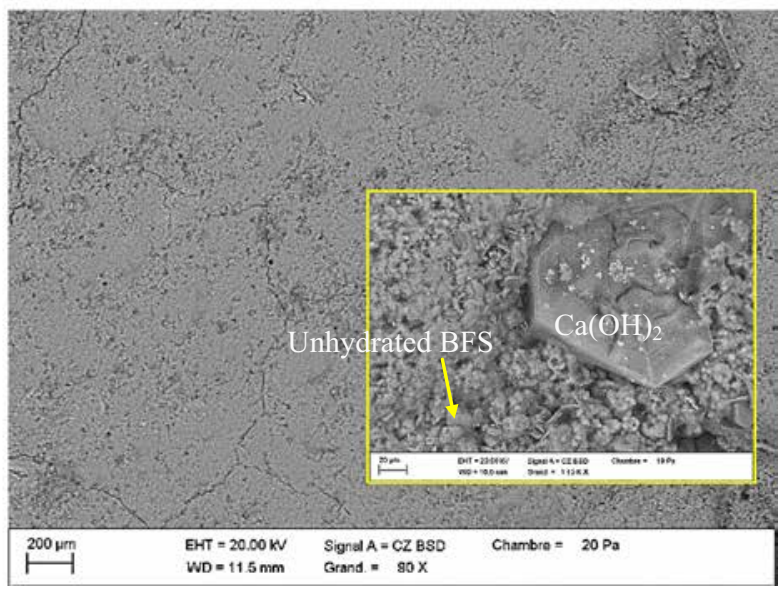

C40BFS60_28 days

Fig. 8. SEM observations of Portland cement and slag-blended matrices.

providing water that in turn promotes first the cement reaction and then the BFS reaction. This mixture, with $\mathrm{S} / \mathrm{C}=2$ and a BFS content of $30 \%$, offers the advantages of a blended matrix at later ages, with a compressive strength at an early age similar to that of the Portland matrix.

\subsection{Chloride transport}

In this study, only total chlorides are investigated. The profiles are plotted in Fig. 11 (a)-(d). As depicted, all profiles clearly demonstrate that chloride ingress increases with time of exposure and moreover chloride concentration decreases at greater depth from the exposed surface.

The chloride diffusion coefficient and the concentration at the sample surface are determined by fitting experimental data using the solution of Fick's second law [48], i.e.:

$$
C(x, t)=C_{s} \times\left[1-\operatorname{erf}\left(\frac{x}{2 \times \sqrt{D_{a} \times t}}\right)\right]
$$

where $C(x, t)$ is the total chloride content at depth $x(m)$ and exposure time $t(s) ; C_{s}$ (\% in $g$ of material) the chloride content at the surface and $D_{a}\left(\mathrm{~m}^{2} / \mathrm{s}\right)$ the apparent diffusion coefficient. 


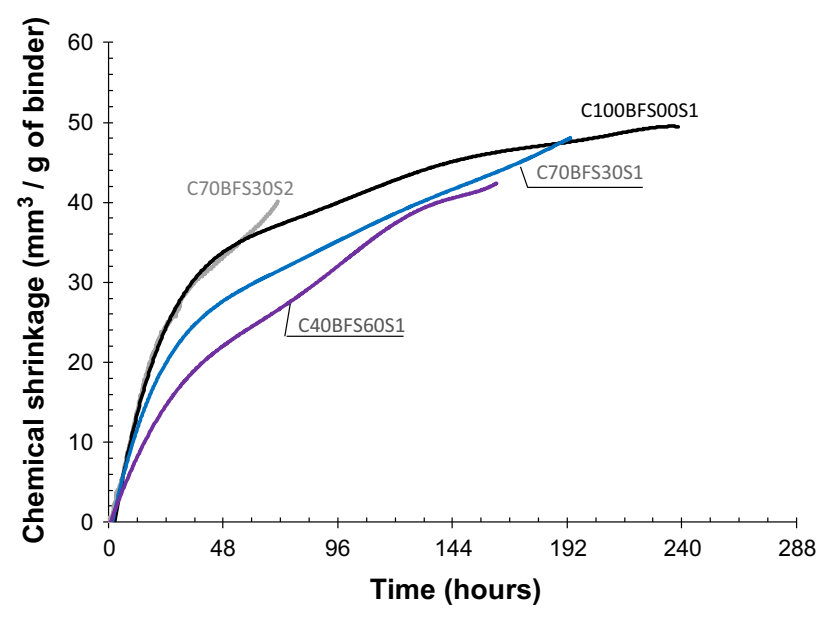

Fig. 9. Chemical shrinkage of OPC and slag-blended mortars.

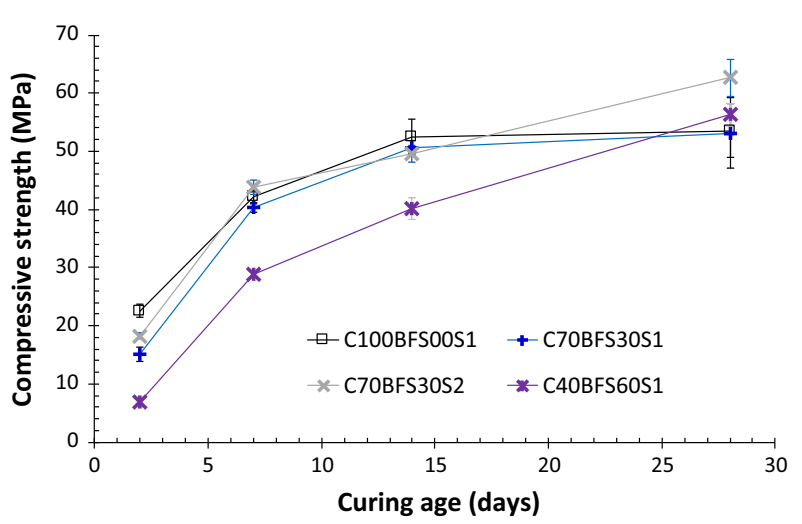

Fig. 10. Compressive strength of OPC and slag-blended mortars.

This special solution of Fick's second law of diffusion corresponds to the instantaneous plane source case in a semi-infinite medium [48]. The chloride content at the surface $\left(C_{s}\right)$ and apparent diffusion coefficient $\left(D_{a}\right)$, for the best fit, are summarized in Table 5.

Exposed after one day of curing, the chloride concentration at the surface of C100BFS00S1 rises from $0.34 \%$ to $0.52 \%$ between 1 and 28 days of exposure. In contrast, the apparent chloride diffusion coefficient decreases by roughly a factor of 4 (from $50 \times 10^{-12} \mathrm{~m}^{2} / \mathrm{s}$ to $12 \times 10^{-12} \mathrm{~m}^{2} / \mathrm{s}$ ) as hydrates develop in the hardening microstructure. The hydration of cement generates $\mathrm{C}$ $\mathrm{S}-\mathrm{H}$ and these hydrates fill the capillary pores, constituting a barrier to chloride ingress. The chloride profiles are compared with the critical chloride concentration, at a designated threshold corresponding to a critical concentration that initiates steel depassivation. The threshold considered herein is that proposed by Thomas and Bamforth [49]: $0.0005 \mathrm{~kg} / \mathrm{kg}$ of mortar (0.05\% by mass of mortar).

As shown in Fig. 11, the progress of the threshold concentration $(0.05 \%)$ is decelerated as hydration progresses, i.e. from $4.5 \mathrm{~mm}$ to $7.5 \mathrm{~mm}$ between 1 and 7 days, and from $8.5 \mathrm{~mm}$ to $9 \mathrm{~mm}$ (only $0.5 \mathrm{~mm}$ ) between Days 14 and 28. For hardened C100BFS00S1, the chloride diffusion coefficient at 28 days is twice as small $\left(6.0 \times 10^{-12} \mathrm{~m}^{2} / \mathrm{s}\right)$ as that of hardening C100BFS00S1.

Substituting cement with BFS greatly increases the chloride diffusion coefficient at one day; $80 \times 10^{-12} \mathrm{~m}^{2} / \mathrm{s}$ and $100 \times 10^{-12} \mathrm{~m}^{2} /$ s for $30 \%$ and $60 \%$ BFS content, respectively. At an early age, BFS particles react slowly and their physical role prevails over the

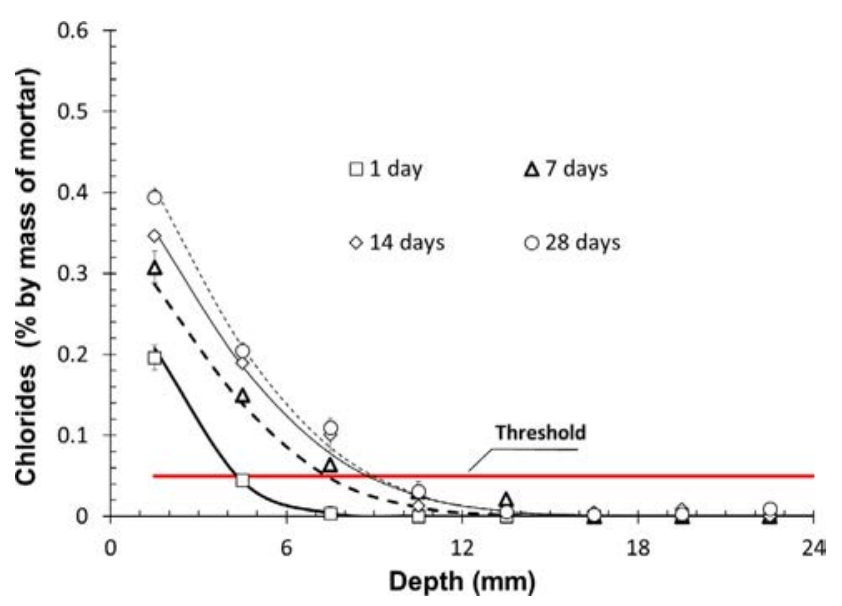

Fig. 11a. Chloride profiles of C100BFS00S1.

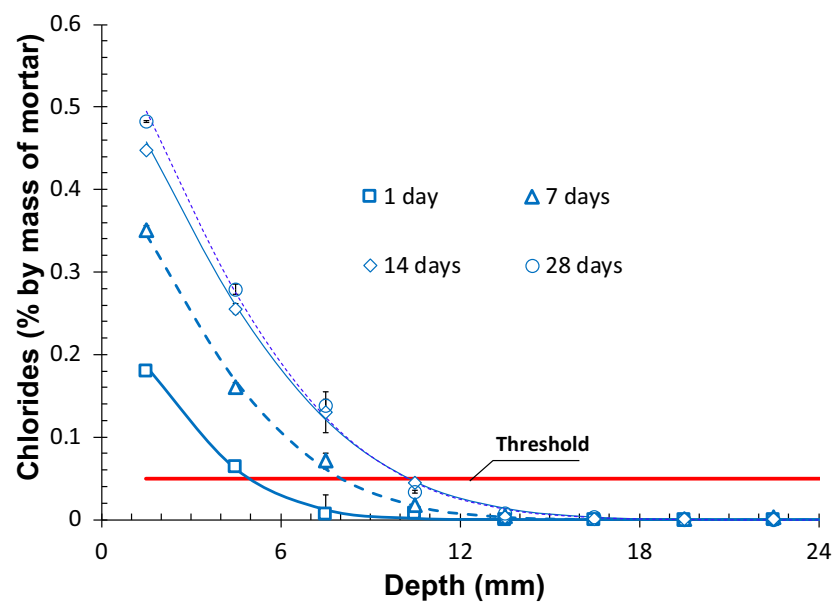

Fig. 11b. Chloride profiles of C70BFS30S1.

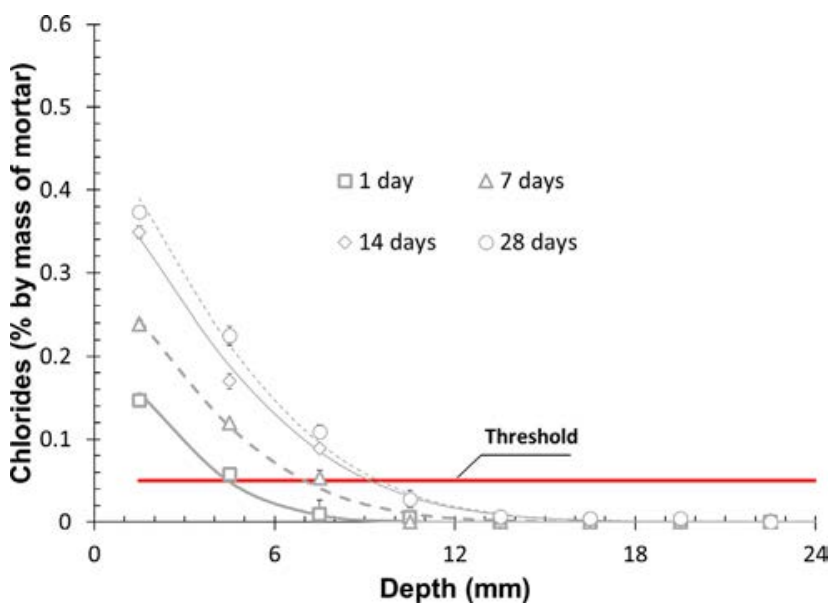

Fig. 11c. Chloride profiles of C70BFS30S2.

chemical role, through improving the mortar packing density. Nevertheless, this effect is insufficiently effective to counter the chloride diffusion, which explains the considerable progress of the threshold concentration in BFS-blended mortars: $8 \mathrm{~mm}$ and $9 \mathrm{~mm}$ respectively for mortars with $30 \%$ and $60 \%$ BFS content, after 7 days of chloride exposure (Fig. 11(b) and 11(d)). Subsequently, 


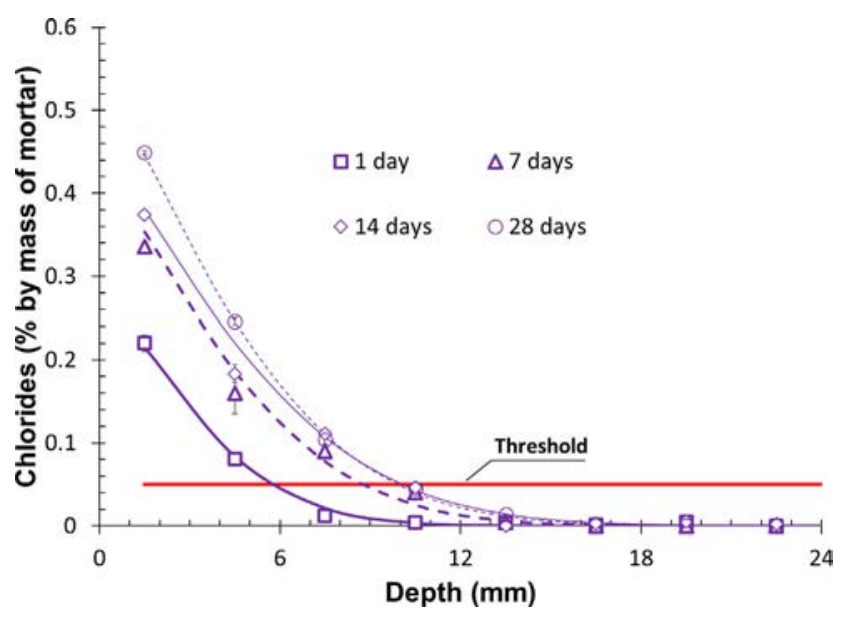

Fig. 11d. Chloride profiles of C40BFS60S1.

BFS particles react with Portlandite, resulting from the reaction of cement with water, to form dense hydrates that both fill pores and refine the microstructure of the blended matrix (Fig. 8). Consequently, the chloride diffusion coefficient falls to $14.2 \times 10^{-12} \mathrm{~m}^{2} / \mathrm{s}$ and $14 \times 10^{-12} \mathrm{~m}^{2} / \mathrm{s}$ respectively for C70BFS30S1 and C40BFS60S1 after a 28-day period of exposure to the chloride solution. For both mortars, the threshold concentration reaches a depth of $10 \mathrm{~mm}$.

In comparing C70BFS30S1 and C70BFS30S2, we note the decrease in the chloride diffusion coefficient as the granular inclusion content rises. For the C70BFS30S2 specimen, the chloride concentration at the surface and the apparent diffusion coefficient after one day equal $0.23 \%$ and $75 \times 10^{-12} \mathrm{~m}^{2} / \mathrm{s}$, respectively. After 28 days of chloride exposure, the apparent diffusion coefficient of mortar containing more sand $(\mathrm{S} / \mathrm{C}=2)$ is slightly lower than that of the mortar with $\mathrm{S} / \mathrm{C}=1$. The threshold concentration reaches a depth of $9.5 \mathrm{~mm}$ (Fig. 11(c)).

Table 5

The parameters of chloride profiles fitting for hardening and hardened mortars.

\begin{tabular}{|c|c|c|c|}
\hline Designation & & $\mathrm{C}_{\mathrm{s}}(\%)$ & $\mathrm{D}_{\mathrm{a}}\left(10^{-12} \mathrm{~m}^{2} / \mathrm{s}\right)$ \\
\hline \multirow[t]{7}{*}{ C100BFS00S1 } & & Hardening & \\
\hline & 1 day & 0.34 & 50.0 \\
\hline & 7 days & 0.40 & 19.0 \\
\hline & 14 days & 0.45 & 12.5 \\
\hline & 28 days & 0.52 & 12.0 \\
\hline & & Hardened & \\
\hline & 28 days & 0.82 & 6.0 \\
\hline \multirow[t]{7}{*}{ C70BFS30S1 } & & Hardening & \\
\hline & 1 day & 0.27 & 80.0 \\
\hline & 7 days & 0.45 & 21.0 \\
\hline & 14 days & 0.57 & 15.0 \\
\hline & 28 days & 0.62 & 14.2 \\
\hline & & Hardened & \\
\hline & 28 days & 0.75 & 5.0 \\
\hline \multirow[t]{7}{*}{ C70BFS30S2 } & & Hardening & \\
\hline & 1 day & 0.23 & 75.0 \\
\hline & 7 days & 0.32 & 20.0 \\
\hline & 14 days & 0.45 & 14.0 \\
\hline & 28 days & 0.49 & 13.8 \\
\hline & & Hardened & \\
\hline & 28 days & 0.5 & 4.9 \\
\hline \multirow[t]{7}{*}{ C40BFS60S1 } & & Hardening & \\
\hline & 1 day & 0.30 & 100.0 \\
\hline & 7 days & 0.45 & 25.0 \\
\hline & 14 days & 0.47 & 16.0 \\
\hline & 28 days & 0.56 & 14.0 \\
\hline & & Hardened & \\
\hline & 28 days & 0.6 & 3.0 \\
\hline
\end{tabular}

\section{Cross analysis: chloride transport vs. Hydration progress}

\subsection{Chloride transport in Portland cement mortar}

To analyze the ingress of chloride with respect to the progress of hydration, the evolution of bound water and chloride diffusion coefficient over time is plotted in the same figure (Fig. 12).

After one day of curing, the OPC mortar is hydrated at $30 \%$ and shrinks rapidly as the cement reacts with water. At this age, the mortar microstructure is extremely porous (Fig. 8) and the internal humidity is high. Therefore, the apparent diffusion coefficient and the depth ingress of chlorides are high, despite the short exposure period. The process governing this ingress is pure diffusion. This result is in accordance with that of [50]; the chloride diffusion raises with the saturation rate.

After 7 days, chloride ingress progresses while at the same time the cement matrix is hardening (degree of hydration $=60 \%$ ), which gradually obstructs the chloride transport pathways. The C-S-H developed by the cement reaction fills the capillary pores and decreases the internal humidity of the mortar. The moisture content of C100BFS00S1 is thus reduced and specimen selfdesiccation becomes more intense, which increases the relative humidity gradient between the exposed surface and the inside of the specimen. This phenomenon is known to accelerate chloride penetration by capillary absorption [6,51], which in turn is counterbalanced by the loss of both porous network interconnectivity and pure diffusion.

As of 14 days, the microstructure is refined enough to constitute a barrier against chloride ingress. Hydration products indeed fill the pores, and the chlorides are only diffused by capillary absorption since the paths are partially saturated. Chloride ingress is thus greatly decelerated, and its progress between 14 days and 28 days is very slow. Fig. 13 depicts the variation in relative apparent chloride diffusion vs. testing age, which corresponds to hydration progress. The relative chloride diffusion is corresponding to the ratio between apparent diffusion coefficient of hardening mortar at time $t$ and the apparent diffusion coefficient of hardened mortar at 28 days. This figure highlights an important result and clearly shows that considering chloride diffusion measured after a long exposure period or in hardened state is not representative when predicting the service life of the structure since chlorides progress rapidly over the first few days, particularly at an early age, thus exacerbating the risk of corrosion initiation. The obtained results feature the same trend of those of Yeih et al. [2] and Mangat et al. [3]. The formers studied the effect of curing duration on chloride ingress into mortars and concretes using a diffusion cell. They measured a decrease in the diffusion coefficient by a factor of 5 as curing duration increases from 7 to 28 days. The latter compared

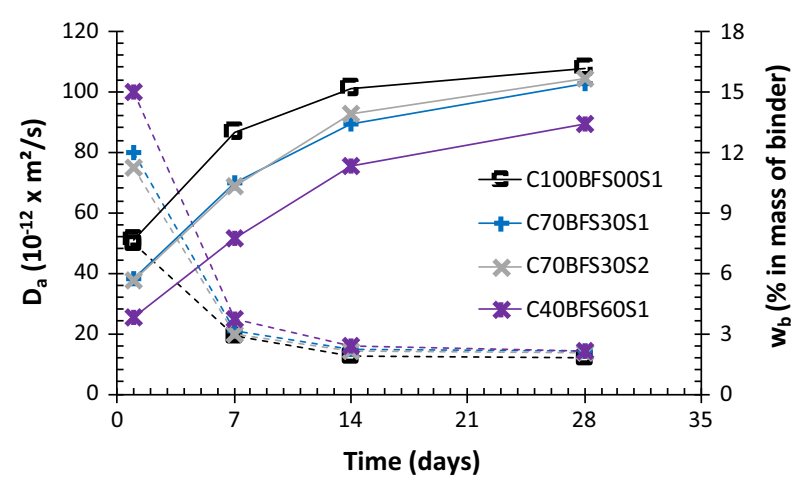

Fig. 12. The progress of apparent diffusion coefficient $\left(D_{a}\right)$ and bound water $\left(W_{b}\right)$ of different mortars. 


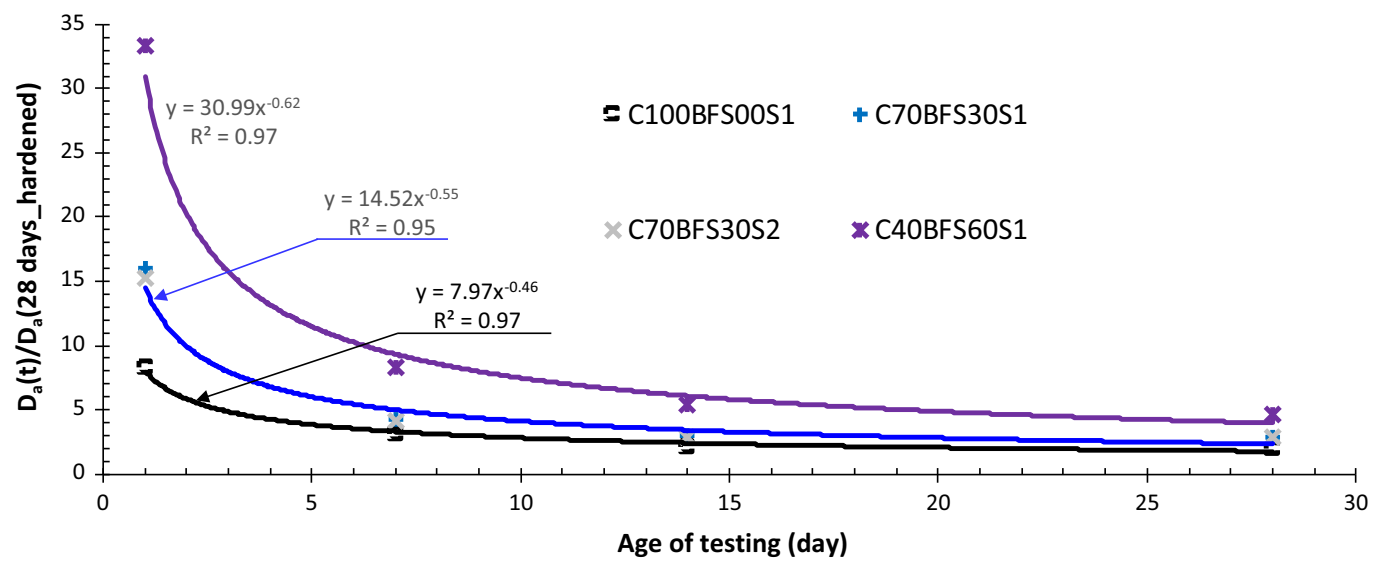

Fig. 13. The relative apparent diffusion coefficient versus time for different mortars.

three curing methods (i.e. $24 \mathrm{~h}$ in the mold, 28 days in air at $20^{\circ} \mathrm{C}$ and $50 \% \mathrm{RH}$, and 28 days in water). They showed that diffusion coefficients for early-age materials are 3-5 times higher than for samples conserved for 28 days before exposure to chloride solution.

Comparing hardening and hardened C100BFS00S1 (Fig. 14) clearly demonstrates the high risk of corrosion initiation in the case of repair materials, since such materials are rapidly exposed to the chloride solution. The high porosity of early-age mortar results in a high chloride diffusion coefficient, which is twice that of hardened mortar. For the hardening mortar the threshold concentration progresses up to $9 \mathrm{~mm}$, while for the hardened one, it only reaches $7.5 \mathrm{~mm}$. Lastly, it is very important to keep in mind that only total chlorides have been considered in this study. The difference between hardened and hardening mortars would be more pronounced if binding isotherms were also taken into account. Binding capacity actually increases with hydrate development. Over the first few days therefore, the amount of bound chlorides remains low and increases with hydration progress.

\subsection{Effect of BFS content}

Substituting cement for BFS decreases the chemical shrinkage of the blended matrix yet slows its hydration reaction, thus resulting in a very porous microstructure with a low content of formed hydrates (i.e. small amount of bound water). At one day of curing, the low hydration reaction of blended mortars (26\% and $17 \%$ for
$30 \%$ and $60 \%$ of BFS content, respectively) promotes the chloride transport process by diffusion since the medium is very permeable and water-saturated (Fig. 12). The measured apparent diffusion coefficients of C70BFS30S1 and C40BFS60S1, at 1 day, are respectively 1.6 and 2 times that of C100BFS00S1, with threshold concentration progress of up to $4.5 \mathrm{~mm}, 5 \mathrm{~mm}$ and $6 \mathrm{~mm}$, for mortars containing respectively $0 \%, 30 \%$ and $60 \%$ of BFS. For the latter, the ingress depth increases to $13.5 \mathrm{~mm}$ after 7 days of exposure and the threshold concentration reaches $9 \mathrm{~mm}$. These results are in agreement with those of Caballero et al. [4], who compared two mortars with a 0.5 water-to-cement ratio, at one day, after one day of exposure to chlorides. They measured a chloride diffusion coefficient of $160 \times 10^{-12} \mathrm{~m}^{2} / \mathrm{s}$ for a CEM I 32.5-mortar and of $310 \times 10^{-12} \mathrm{~m}^{2} / \mathrm{s}$ for a CEM III 42.5-mortar (CEM III contains $65 \%-80 \%$ BFS).

After 14 days, the reaction of BFS particles with Portlandite makes the microstructure denser, and the hydrates (C-S-A-H) formed are known to be of high density, fill the pores, and decrease chloride diffusion. Even if it is assumed that pore desaturation increases capillary depression and hence the transport of chlorides by convection, this phenomenon is however counterbalanced by the decrease in both porous network interconnectivity and chloride transport by pure diffusion (since the pores are not watersaturated). As a result, the diffusion coefficients of the blended matrix decrease more rapidly than those of the OPC with hydration underway (Figs. 12 and 13). At 28 days, the diffusion coefficients differ slightly. Nevertheless, a tremendous difference is observed
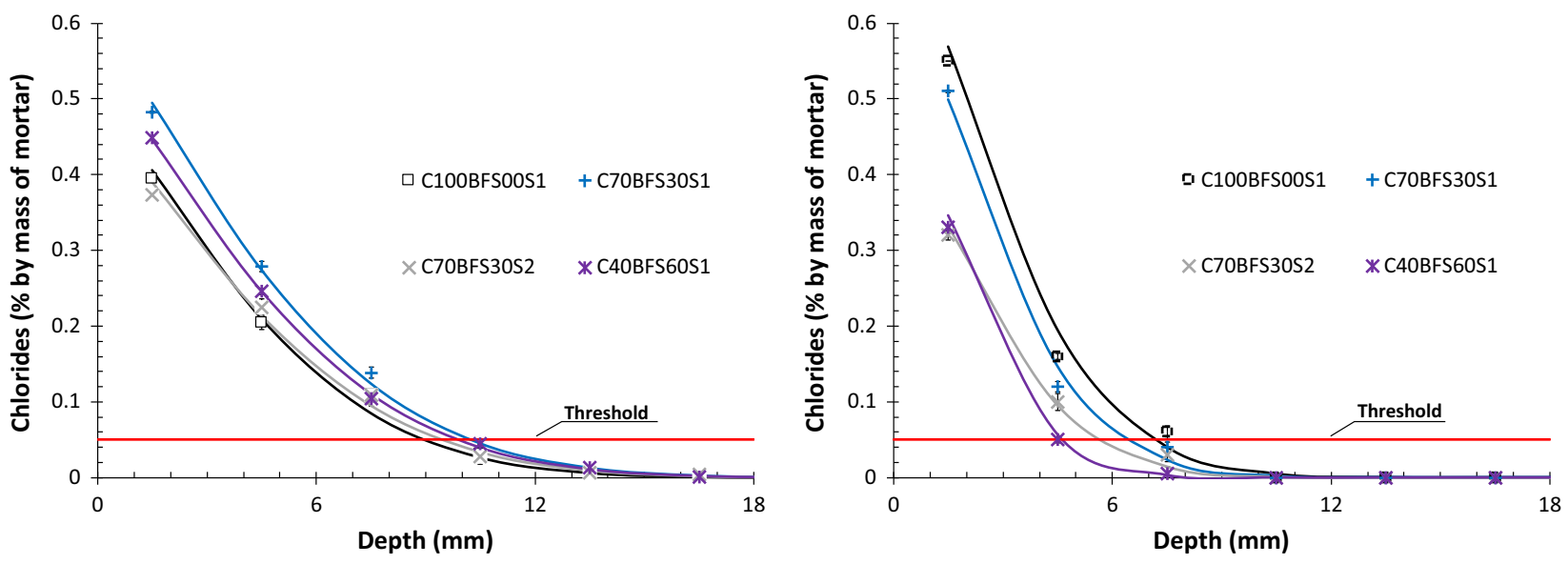

Fig. 14. Comparison of chloride profiles after 28 days of exposure for hardening (on the left) and hardened (on the right) mortars. 
when comparing hardened and hardening mortars, particularly blended ones. As presented in Table 5, the chloride diffusion coefficients of hardening mortars are respectively 2, 2.8 and 4.7 times greater than those of hardened mortars with $0 \%, 30 \%$ and $60 \%$ BFS content.

\subsection{Effect of granular inclusion concentration}

Except at Day 1, the apparent diffusion coefficients of C70BFS30S1 lie very close to those of C70BFS30S2 over all exposure periods. As explained above, the presence of sand promotes the early reaction of cement by both site and dispersion effects. The formed hydrates fill pores, decrease the porosity of ITZ, make the microstructure denser and counterbalance the more extensive shrinkage. Hence, the mortar with higher sand content exhibits more resistance against chlorides. The results obtained are in agreement with those found by Gao et al. [52] and Yang and Su [53]. The former measured a decrease in ITZ porosity with increased sand content of mortars, while the latter carried out migration tests on mortars with different sand contents. They measured a $19 \%$ decrease in the normalized mortar migration coefficient with sand content increasing from $20 \%$ to $40 \%$.

This study has focused on chloride ingress in early-age blended mortars, as compared to OPC mortars. The objective has not only been to highlight the high diffusion coefficient of repair materials that may come into contact with chloride solution at an early age, but also to show the extensive ingress of chlorides by measuring the maximum depth reached by the chloride threshold concentration. For the sake of simplification, this concentration is assumed to lie at $0.05 \%$. To further this research, it would be worthwhile to recall herein the actual meaning of this concentration, i.e. one corresponding to the depassivation of steel and the initiation of corrosion. Moreover, it depends on the pore solution chemistry. The recent publication by Scott and Alexander [54] has highlighted the effect of BFS content on the binder-pore solution chemistry $[55,56]$. The sulfides and thiosulfates typically found in BFSblended pastes seem to lower the chloride threshold concentration and then increase the corrosion rate.

In conclusion, an investigation into the pore solution chemistry of binders in the presence of BFS would be needed to assess the corrosion risk in the case of blended materials.

\section{Conclusion}

This article has investigated the effect of slag content on chloride ingress in blended-cement mortars at an early age. The analysis of results obtained leads to the following conclusions:

- The low reactivity of BFS particles delays the formation of hydrates that fill the capillary pores and refine the microstructure of the blended matrix. Consequently, the porous network is connected and pores are water-saturated, which together promotes chloride diffusion at an early age.

- As the hydration progresses, the microstructure becomes refined and the hydrates formed obstruct the chloride diffusion paths. At the same time, the sample undergoes a selfdesiccation deformation due to the lower internal humidity. This phenomenon generates capillary tension and influences the penetration process of chlorides, which then becomes a combination of pure diffusion and capillary absorption. Since the measured chloride diffusion coefficient decreases over time, it can be concluded that the hydration phenomenon is quicker than the diffusion phenomenon. Hence, chloride ingress by means of diffusion and capillary absorption is largely counterbalanced by obstruction of the porous network.
- Increasing the granular inclusion content improves the hydration reaction of blended mixtures, while increasing their compressive strength and resistance to chlorides, particularly during the early age. Nevertheless, this resistance does not reach that of the OPC mortar.

- At later ages, BFS-blended mortars feature a more refined microstructure and higher binding capacity, which in turn reduce their chloride diffusion coefficient in comparison with the Portland cement mortar.

The results of this research work have highlighted the risk of chloride contamination of blended materials, despite the use of slag, which is expected to improve these properties over the long term. These results could be used to validate models, thus offering a better prediction of the service life of structures, in considering the chloride diffusion coefficient to be variable over time and particularly high during the very early age and in the presence of BFS.

\section{Declaration of Competing Interest}

No conflict of interest

\section{References}

[1] Y. Yang, M. Wang, Pore-scale modelling of chloride ion diffusion in cement microstructures, Cem. Concr. Compos. 85 (2018) 92-104.

[2] J. Caballero, R.B. Polder, G.A. Leegwater, A.L.A. Fraaij, Chloride penetration into cementitious mortar at early age, Heron 57 (2012) 185-196.

[3] W.D. Yeih, R. Huang, J.J. Chang, A study of chloride diffusion properties of concrete at early age, Jour. Mar. Sci Techn. 2 (1994) 61-67.

[4] P.S. Mangat, M.C. Limbachiya, Effect of initial curing on chloride diffusion in concrete repair materials, Cem. Concr. Res. 29 (1999) 1475-1485.

[5] J.M. Khatib, P.S. Mangat, Influence of high-temperature and low-humidity curing on chloride penetration in blended cement concrete, Cem. Concr. Res. 32 (2002) 1743-1753.

[6] A. Ben Fraj, S. Bonnet, A. Khelidj, New approach for coupled chloride/moisture transport in non-saturated concrete with and without slag, Constr. Build. Mater. 35 (2012) 761-771.

[7] A.R. Bagheri, H. Zanganeh, M.M. Moalemi, Mechanical and durability properties of ternary concretes containing silica fume and low reactivity blast furnace slag, Cem. Concr. Compos. 34 (2012) 663-670.

[8] B. Touil, F. Ghomari, A. Bezzar, A. Khelidj, S. Bonnet, Effect of temperature on chloride diffusion in saturated concrete, ACI Mater. J. 114 (2017) 713-721.

[9] O.R. Ogirigbo, L. Black, Chloride binding and diffusion in slag blends: Influence of slag composition and temperature, Constr. Build. Mater. 149 (2017) 816825.

[10] V.Q. Tran, A. Soive, V. Baroghel-Bouny, Modelisation of chloride reactive transport in concrete including thermodynamic equilibrium, kinetic control and surface complexation, Cem. Concr. Res. 110 (2018) 70-85.

[11] M.A. Sanjuan, E. Estévez, C. Argiz, D. Del Barrio, Effect of curing time on granulated blast-furnace slag cement mortars carbonation, Cem. Concr. Compos. 90 (2018) 257-265.

[12] B. Liu, G. Luo, Y. Xie, Effect of curing conditions on the permeability of concrete with high volume mineral admixtures, Constr. Build. Mater. 167 (2018) 359371.

[13] E. Gartner, Industrially interesting approaches to "low- $\mathrm{CO}_{2}$ " cements, Cem. Concr. Res. 34 (2004) 1489-1498.

[14] J.S. Damtoft, J. Lukasik, D. Herfort, D. Sorrentino, E. Gartner, Sustainable development and climate initiatives, Cem. Concr. Res. 38 (2008) 115-127.

[15] A. Djerbi, S. Bonnet, A. Khelidj, V. Baroghel-Bouny, Influence of traversing crack on chloride diffusion into concrete, Cem. Concr. Res. 38 (2008) 877-883.

[16] M. Schneider, M. Romer, M. Tschudin, H. Bolio, Sustainable cement production-present and future, Cem. Concr. Res. 41 (2011) 642-650.

[17] V.G. Papadakis, Effect of supplementary cementing materials on concrete resistance against carbonation and chloride ingress, Cem. Concr. Res. 30 (2000) 291-299.

[18] H.-J. Chen, S.-S. Huang, C.-W. Tang, M.A. Malek, L.-W. Ean, Effect of curing environments on strength, porosity and chloride ingress resistance of blast furnace slag cement concretes: A construction site study, Constr. Build. Mater. 35 (2012) 1063-1070.

[19] J. Wu, H. Li, Z. Wang, J. Liu, Transport model chloride ions in concrete under loads and drying-wetting cycles, Constr. Build. Mater. 112 (2016) 733-738.

[20] O.M. Abdulkareem, A. Ben Fraj, M. Bouasker, A. Khelidj, Effect of chemical and thermal activation on microstructural and mechanical properties of more sustainable UHPC, Constr. Build. Mater. 169 (2018) 567-577.

[21] P. Mounanga, M.I.A. Khokhar, R. El Hachem, A. Loukili, Improvement of the early-age reactivity of fly ash and blast furnace slag cementitious systems using limestone filler, Mater. Struct. 44 (2011) 437-453. 
[22] B. Kolani, L. Buffo-Lacarrière, A. Sellier, G. Escadeillas, L. Boutillon, L. Linger, Hydration of slag-blended cements, Cem. Concr. Compos. 34 (2012) 10091018.

[23] O.M. Abdulkareem, A. Ben Fraj, M. Bouasker, A. Khelidj, Mixture design and early age investigation of more sustainable UHPC, Constr. Build. Mater. 163 (2018) 235-246.

[24] T. Merzouki, M. Bouasker, N. Khalifa, P. Mounanga, Contribution to the modeling of hydration and chemical shrinkage of slag-blended cement at early age, Constr. Build. Mater. 44 (2013) 368-380.

[25] Afnor, EN 206, Concrete - Specification, performance, production and conformity, 2014.

[26] A.K. Schindler, K.J. Folliard, Heat of hydration models for cementitious materials, ACI Mater. J. 102 (2005) 24-33.

[27] T. Kishi, K. Maekawa, Thermal and mechanical modeling of Young concrete based on hydration process of multi-component cement minerals, Intern. RILEM Sympos. (1995) 11-18.

[28] P. Mounanga, A. Khelidj, A. Loukili, V. Baroghel-Bouny, Predicting $\mathrm{Ca}(\mathrm{OH}) 2$ content and chemical shrinkage of hydrating cement pastes using analytical approach, Cem Concr. Res. 34 (2004) 255-265.

[29] Afnor, EN 196-1, European standard, Methods of testing cement - Part 1: Determination of strength, 2016.

[30] O. Vennesland, M.-A. Climent, C. Andrade, Recommendation of RILEM TC 178 TMC: Testing and modelling chloride penetration in concrete. Methods for obtaining dust samples by means of grinding concrete in order to determine the chloride concentration profile, Mater. Struct. 46 (2012) 337-344.

[31] RILEM 178-TMC 2002, Testing and modelling chloride penetration in concrete: Analysis of total chloride in concrete, Mater. Struct. 35 (2002) $583-585$.

[32] S. Bonnet, F. Schoefs, M. Salta, Sources of uncertainties for total chloride profile measurements in concrete: quantization and impact on probability assessment of corrosion initiation, Eur. J. Env. Civ. Eng. (2017), https://doi. org/10.1080/15732479.2017.1377737.

[33] I. Pane, W. Hansen, Investigation of blended cement hydration by isothermal calorimetry and thermal analysis, Cem. Concr. Res. 35 (2005) 1155-1164.

[34] B. Chen, J. Liu, Experimental application of mineral admixtures in lightweight concrete with high strength and workability, Constr. Build. Mater. 22 (2008) $1108-1113$.

[35] Y. Ballim, P.C. Graham, The effects of supplementary cementing materials in modifying the heat of hydration of concrete, Mater. Struct. 42 (2009) 803-811.

[36] X.-Y. Wang, H.-S. Lee, K.-B. Park, J.-J. Kim, J.S. Golden, A multi-phase kineti model to simulate hydration of slag-cement blends, Cem. Concr. Compos. 32 (2010) 468-477.

[37] M. Bouasker, Etude numérique et expérimentale du retrait endogène au très jeune âge des pâtes de ciment avec et sans inclusions, Université de Nantes, Thèse de doctorat, 2007.

[38] E. Holt, Early age autogenous shrinkage of concrete, Publication of the technical research centre of Finland, 2001.

[39] M. Garg, A. Pundir, Investigation of properties of fluorogypsum-slag composite binders - hydration, strength and microstructure, Cem. Concr. Compos. 45 (2014) 227-233.
[40] P. Duan, Z. Shui, W. Chen, C. Shen, Enhancing microstructure and durability of concrete from ground granulated blast furnace slag and metakaolin as cement replacement materials, Jour. Mater. Res. Techn. 2 (2013) 52-59.

[41] Y.-J. Tang, X.-B. Zuo, S.-L. He, O. Ayinde, G.-J. Yin, Influence of slag content and water-binder ratio on leaching behavior of cement pastes, Constr. Build. Mater. 129 (2016) 61-69.

[42] M. Whittaker, M. Zajac, M. Ben, Haha, The role of the alumina content of slag, plus the presence of additional sulfate on the hydration and microstructure of Portland cement-slag blends, Cem. Concr. Res. 66 (2014) 91-101.

[43] O.R. Ogirigbo, L. Black, Influence of slag composition and temperature on the hydration and microstructure of slag blended cements, Constr. Build. Mater. 126 (2016) 496-507.

[44] P. Lura, K. Van Breugel, I. Maruyama, Effect of curing temperature and type of cement on early age shrinkage of high performance concrete, Cem. Concr. Res. 31 (2001) 1867-1872.

[45] A. Pertué A., Etude expérimentale du retrait endogène, du fluage propre et de la fissuration des matrices cimentaires aux jeune et très jeune âges, Thèse de Doctorat, Université de Nantes, 2008.

[46] A. Bentur (Ed.), Early Age Cracking in Cementitious Systems, Report of RILEM Technical Committee TC 181-EAS, RILEM Publications S.A.R.L., 2003.

[47] S. Zhutovsky, K. Kovler, A. Bentur, Influence of cement paste matrix properties on the autogenous curing of high-performance concrete, Cem. Concr. Compos. 26 (2004) 499-507.

[48] J. Crank, The Mathematics of Diffusion, second ed., Oxford Science Publications, UK, 1975.

[49] M.D.A. Thomas, P.B. Bamforth, Modelling chloride diffusion in concrete: Effect of fly ash and slag, Cem. Concr. Res. 29 (1999) 487-495.

[50] N. Olsson, B. Lothenbach, V. Baroghel-Bouny, L.-O. Nilsson, Unsaturated ion diffusion in cementitious materials - The effect of slag and silica fume, Cem. Concr. Res. 108 (2018) 31-37.

[51] M. Saillio, V. Baroghel-Bouny, F. Barberon, Chloride binding in sound and carbonated cementitious materials with various types of binder, Constr. Build. Mater. 68 (2014) 82-91.

[52] Y. Gao, G. De Schutter, G. Ye, Z. Tan, K. Wu, The ITZ microstructure, thickness and porosity in blended cementitious composite: Effects of curing age, water to binder ratio and aggregate content, Compos. Part B 60 (2014) 1-13.

[53] C.C. Yang, J.K. Su, Approximate migration coefficient of interfacial transition zone and the effect of aggregate content on the migration coefficient of mortar, Cem. Concr. Res. 32 (2002) 1559-1565.

[54] A Scott, M.G. Alexander, Effect of supplementary cementitious materials (binder type) on the pore solution chemistry and the corrosion of steel in alkaline environments, Cem. Concr. Res. 89 (2016) 45-55.

[55] K. Byfors, C. Hansson, J. Tritthart, Pore solution expression as a method to determine the influence of mineral additives on chloride binding, Cem. Concr. Res. 16 (1986) 760-770.

[56] J. Duchesne, M. Berube, The effectiveness of supplementary cementing materials in suppressing expansion due to ASR: another look at the reaction mechanisms part 2: pore solution chemistry, Cem. Concr. Res. 24 (1994) 221 230. 